\title{
DEBATE SOBRE LOS INTERNADOS Y LA ESCUELA NUEVA
}

Emile Durkheim y Paul Desjardins

DESJARDINS: Yo veo claramente donde está la ventaja para el niño mismo, ¿pero donde está el interés general de la sociedad? ¿Me concederéis aquel principio que requiere (que el interés de la sociedad demanda), que la obra de la educación sea, si es posible, sustraída a aquello que deshace la educación, es decir, en este caso al bullicio de las ciudades? ¿Me concederéis el principio de que el educador debe tomar deliberadamente su punto de apoyo fuera de la realidad social inestable a fin de que sea capaz de resistirla? Sobre este asunto he tomado ya partido y sé bien lo que haría. Pero surgen los problemas prácticos.

Si se generaliza el sistema de enviar los niños internos al campo en lugar de dejarlos externos en la ciudad, ¿qué forma de agrupación será la mejor, la más natural? En las escuelas nuevas, nosotros tenemos dos grupos: el familiar y el escolar. El jefe del hogar es distinto del profesor de clase. ¿Es esta dualidad buena, perjudicial?

¿No se podrían concebir dos grupos de internados, uno familiar y otro escolar? ¿Habría algo de perjudicial en esta organización?

DURKHEIM: La pregunta planteada por mi amigo Desjardins parece tener un interés platónico. Es evidente que en Francia no podemos librarnos de los internados. Los jesuitas quisieron evitarlos, pero se vieron obligados a ceder ante las quejas de las familias y de las municipalidades. Las Escuelas Centrales de la Revolución no tenían internados, y esta fue una de las causas de su fracaso.

Todo el problema está en saber cómo organizar los internados. Se propone llevarlos al campo, pero también se sabe lo que cuestan los internados rurales, y allí no serían accesibles más que a una minoría de niños afortunados. No es una solución que pueda ser generalizada; lo que me parece que le resta mucho interés.

DESJARDINS: ¿Es necesario extender la vida familiar al internado?

DURKHEIM: Esto no podemos ni pensarlo: una organización como esta de la cual venimos hablando es mucho más costosa. Por otro lado, nuestros grandes internados son contraproducentes. Sería necesario encontrar una solución intermedia, lo que no es imposible. 